DOI: 10.12957/demetra.2018.31290

\title{
Desenvolvimento e aceitação sensorial de kefir com geleia de goiaba e avaliação de compostos bioativos
}

\section{Development and sensory acceptance of kefir with guava jelly and evaluation of bioactive compounds}

\author{
Carollyne dos Santos Cavararo' \\ Jorge Pinho da Silva Júnior? \\ Josiane Roberto Domingues \\ Claudete Corrêa de Jesus Chiappini ${ }^{3}$ \\ ' Universidade Federal Fluminense, Faculdade \\ de Nutrição Emília de Jesus Ferreiro, Curso de \\ Graduação em Nutrição. Niterói, RJ, Brasil. \\ ${ }^{2}$ Universidade Federal Fluminense, Faculdade \\ de Farmácia, Departamento de Bromatologia. \\ Niterói, RJ, Brasil. \\ ${ }^{3}$ Universidade Federal Fluminense, Faculdade de \\ Nutrição Emília de Jesus Ferreiro, Departamento \\ de Nutrição e Dietética. Niterói, RJ, Brasil. \\ Correspondência / Correspondence \\ Carollyne dos Santos Cavararo \\ E-mail: carol.cavararo@gmail.com
}

\section{Resumo}

Introdução: Compostos bioativos são definidos como nutrientes ou não nutrientes que possuem ação metabólica ou fisiológica específica no organismo, como as ações antitumoral, antifúngica, antibacteriana, imunomoduladora, anti-inflamatória e antioxidante. Os probióticos presentes nos leites fermentados e os carotenoides presentes nas frutas são descritos, na literatura, como benéficos à saúde. Objetivo: Desenvolver, avaliar a aceitação sensorial, a atividade antioxidante e determinados compostos bioativos de kefir com geleia de goiaba. Metodologia: O kefir foi desenvolvido e sua aceitação avaliada pelo teste de escala hedônica; a composição centesimal foi determinada pelos métodos oficiais; a atividade antioxidante foi avaliada pelo ensaio ORAC; os compostos fenólicos totais e os carotenoides totais foram determinados por método espectrofotométrico. Resultados: A adição dos $30 \%$ de geleia de goiaba elevou a atividade antioxidante, os compostos fenólicos e os carotenoides totais do kefir. O produto elaborado foi bem aceito pelos consumidores, que também comprariam o produto caso este fosse comercializado. Conclusão: Concluiu-se que adição de geleia contribuiu para o aumento dos compostos bioativos avaliados e a bebida fermentada poderia contribuir para a saúde dos consumidores.

Palavras-chave: Kefir. Compostos bioativos. Atividade antioxidante. Compostos fenólicos. Carotenoides. Aceitação sensorial. 


\section{Abstract}

Introduction: Bioactive compounds are defined as nutrients or non-nutrients that have specific metabolic or physiological actions in the body such as antitumor, antifungal, antibacterial, immunomodulatory, anti-inflammatory and antioxidant actions. The probiotics in fermented milks and carotenoids in fruits are described in the literature as beneficial to health. Objective: To develop, evaluate the sensory acceptance, the antioxidant activity and some bioactive compounds of kefir with guava jelly. Methodology: Kefir was developed and its acceptance evaluated by the hedonic scale test; the centesimal composition was determined by the official methods; the antioxidant activity was evaluated by the ORAC assay; the total phenolic compounds and the total carotenoids were determined by spectrophotometric method. Results: The addition of $30 \%$ guava jelly increased the antioxidant activity, phenolic compounds and total kefir carotenoids. The product was well accepted by consumers, who would also buy it if it were marketed. Conclusion: It was concluded that adding jelly contributed to the increase of the bioactive compounds evaluated, and the fermented beverage could contribute to the health of the consumers.

Keywords: Kefir. Bioactive compounds. Antioxidant activity. Phenolic compounds. Carotenoids. Sensory acceptance.

\section{Introdução}

Alimentos que promovam efeitos positivos na saúde do consumidor são a nova tendência do mercado e obtêm êxito devido à preocupação progressiva com o estado nutricional e o bem-estar, juntamente com a crescente comprovação científica das relações existentes entre dieta e saúde. ${ }^{1}$

O Regulamento Técnico de Substâncias Bioativas e Probióticos Isolados com Alegação de Propriedades Funcional e ou de Saúde define que essas substâncias são os nutrientes ou não nutrientes que possuem ação metabólica ou fisiológica específica no organismo. Estes são classificados em carotenoides, fitoesteróis, flavonoides, fosfolipídeos, organossulfurados, polifenóis e probióticos. ${ }^{2}$ Os probióticos, por sua vez, são conceituados como microrganismos vivos, que podem trazer benefícios à saúde quando administrados de modo contínuo em quantidades adequadas. ${ }^{3,4}$

Estudos consideram os leites fermentados como principal veículo para a incorporação de culturas probióticas que podem apresentar atividade antioxidante e trazer benefícios ao consumidor. ${ }^{5} \mathrm{~A}$ 
Instrução Normativa no 46, de 23 de outubro de 2007, ${ }^{6}$ define o kefir como um leite fermentado obtido pela coagulação e diminuição do $\mathrm{pH}$ do leite cuja fermentação se realiza com cultivos ácidos lácticos elaborados pelos microrganismos presentes nos grãos de kefir. O grão é formado por uma estrutura complexa de bactérias e leveduras, totalizando cerca de 30 espécies de microrganismos incorporados em uma matriz de polissacarídeos e proteínas, ${ }^{7}$ propriedades que tornam os grãos de kefir potentes probióticos. Seus compostos bioativos são resultantes da fermentação do leite pelos grãos de kefir. Nesse processo, os microrganismos produzem substâncias que conferem textura e sabor característicos ao fermentado. Apesar de poucos estudos, pesquisas científicas evidenciam que as enzimas proteolíticas dos microrganismos que realizam a fermentação podem contribuir para a liberação de peptídeos bioativos, conferindo ao kefir efeitos antioxidantes benéficos à saúde. ${ }^{8}$ Durante o processo de fermentação, também ocorre a produção do kefiran por Lactobacillus kefiranofaciens, que se constitui em heteropolissacarídeo com proporções equivalentes de glicose e galactose, e se distingue por sua ação antitumoral, antifúngica, antibacteriana, imunomoduladora, anti-inflamatória e antioxidante. ${ }^{9,10}$

Estudos envolvendo a ingestão de produtos alimentícios contendo culturas probióticas específicas resultaram numa redução na intolerância à lactose, aumento da atividade do sistema imunológico, da atividade antimicrobiana e das atividades anticarcinogênica e antimutagênica, redução do nível de colesterol no sangue, melhora da infecção ulcerosa gástrica causada por Helicobacter pylori, e no tratamento da síndrome do intestino irritável, além da ação de desintoxicação intestinal, através da restauração do equilíbrio da mucosa. .11 $^{1,11}$

O consumo de leites fermentados começou a crescer a partir de 1960, quando a adição de frutas passou a amenizar o sabor ácido característico desta bebida, proporcionando maior aceitação sensorial pelos consumidores que não apreciam o sabor do leite fermentado em sua forma natural. ${ }^{12}$ A goiaba (Psidium guajava L) é fruta nativa da América do Sul, cultivada principalmente em países de clima tropical, que apresenta alta aceitação, seja consumida in natura ou processada. Estudos demonstram que ela apresenta propriedades nutritivas e biofuncionais, devido ao seu conteúdo em compostos fenólicos, carotenoides, óleos essenciais, ácidos triterpenoides, vitamina C e minerais como cálcio, fósforo e ferro, sendo considerada, portanto, uma das frutas com maior potencial antioxidante. $^{13,14}$

Os estudos dos compostos bioativos são importantes para ampliar o conhecimento das propriedades dos alimentos e incentivar sua introdução na alimentação da população. Levando em consideração o exposto, este estudo teve como objetivo desenvolver o kefir com geleia de goiaba, avaliar a aceitação sensorial, a atividade antioxidante, os compostos fenólicos totais e carotenoides totais presentes no produto alimentício. 


\section{Metodologia}

\section{Material}

O estudo foi realizado no Laboratório de Alimentos e Dietética, no Laboratório de Análise Sensorial da Faculdade de Nutrição e no Laboratório de Biotecnologia de Alimentos da Faculdade de Farmácia, da Universidade Federal Fluminense. O kefir foi preparado utilizando leite fluido integral esterilizado e grãos de kefir viáveis e ativos numa proporção de $5 \%$, de modo a favorecer o mínimo de $10^{7}$ bactérias lácticas totais (UFC/g) e $10^{4}$ leveduras específicas (UFC/g) no produto final, conforme preconizado por Brasil ${ }^{6}$ e Nielsen et al. ${ }^{7}$ Em seguida, o inóculo foi incubado para fermentar em temperatura ambiente $\left(25^{ \pm} 1^{\circ} \mathrm{C}\right)$ por 24 horas e para maturar em refrigeração $\left(4 \pm 1^{\circ} \mathrm{C}\right)$ por 24 horas. Após, o leite fermentado foi coado para a retirada dos grãos de kefir, que foram incubados em novo substrato para manutenção da viabilidade. O produto da fermentação foi dessorado durante quatro horas em refrigeração para acabamento final e foi armazenado em frascos de vidro a $4 \pm 1^{\circ} \mathrm{C}$. Para o preparo da geleia de goiaba, as goiabas foram adquiridas no comércio de Niterói-RJ, e depois de higienizadas e descascadas, foram cozidas na proporção de quatro partes da fruta para uma parte de sacarose. Porções do kefir foram acrescidas de 0,5\% de essência de baunilha (Dr. Oetker, BRA) e 30\% de geleia de goiaba para os experimentos seguintes.

\section{Métodos}

Para a realização desta etapa, o projeto foi submetido ao Comitê de Ética da Faculdade de Medicina da Universidade Federal Fluminense e aprovado sob o número 45481815.7.0000.5243. Os consumidores que concordaram em participar do teste sensorial assinaram o termo de consentimento livre e esclarecido. A aceitação do kefir com geleia de goiaba foi determinada por 92 consumidores, que receberam as amostras randomizadas de forma monádica. ${ }^{15}$

Foi utilizada uma escala hedônica estruturada mista de nove pontos, em ordem decrescente, com as extremidades ancoradas nos termos "gostei muitíssimo" = 1, "desgostei muitíssimo" $=9 \mathrm{e}$ "não gostei nem desgostei" = 5 no meio da escala. ${ }^{15} \mathrm{~A}$ ficha de avaliação incluiu a pergunta sobre qual atributo sensorial o provador mais gostou ou mais desgostou. Para a intenção de compra, foi utilizada uma escala estruturada mista de sete pontos, com as extremidades ancoradas nos termos "compraria sempre" = 1, "não compraria" = 7 e "compraria ocasionalmente" = 4 no meio da escala, por 91 consumidores. ${ }^{16}$ Os dados foram tabulados em planilha no programa Microsoft Excel, e em seguida transformados em gráfico.

Para a caracterização do kefir com geleia de goiaba, foi realizada análise da composição centesimal, em triplicata, segundo os métodos da Association of Official Analytical Chemists. ${ }^{17} \mathrm{~A}$ umidade foi determinada pelo método gravimétrico após aquecimento a $105^{\circ} \mathrm{C}$. As cinzas foram 
determinadas pelo método gravimétrico, após incineração em mufla a $550^{\circ} \mathrm{C}$. O nitrogênio total foi obtido pelo método de Kjeldahl, utilizando-se o fator 6,25 para determinar o valor em proteínas. O extrato etéreo foi obtido por método gravimétrico após extração da gordura pelo método de Soxhlet com éter de petróleo. Os glicídios totais foram obtidos pelo cálculo da diferença, em base úmida, sendo obtida a fração NIFEXT (nitrogen free extract).

Amostras de kefir, geleia de goiaba e kefir com a geleia foram congelados e liofilizados em liofilizador Liotop ${ }^{\circledR}$ (Liobras, BRA). A obtenção do extrato das amostras de kefir, de geleia de goiaba e de kefir com geleia de goiaba foi realizada conforme Ribeiro et al., ${ }^{18}$ sendo utilizados cinco gramas de amostra liofilizada, solvente metanol 50\% (v/v) e acetona $70 \%$ (v/v). A atividade antioxidante foi avaliada pelo ensaio ORAC (Oxygen Radical Antioxidant Capacity), de acordo com a metodologia descrita por Dávalos et al., ${ }^{19}$ com a utilização de tampão de fosfato PBS (pH 7,4), trolox e fluoresceína. A leitura foi realizada pelo leitor de microplacas FLUOstar Optima® (BMG Labtech, ENG) com detector de fluorescência. A análise foi realizada em triplicata e os resultados expressos em $\mu \mathrm{mol}$ de equivalentes de trolox por grama de amostra. Para a determinação dos compostos fenólicos totais, foram utilizados os extratos das amostras juntamente com o reagente de Folin-Ciocalteu a $50 \%$ (v/v) e cerca de $4 \mathrm{~mL}$ da solução aquosa de carbonato de sódio 7,5\% (m/v) ${ }^{20}$ sendo a absorbância das amostras medida em espectrofotômetro UV-2600 (Shimadzu, BRA) a $750 \mathrm{~nm}$. As análises foram realizadas em triplicata e os resultados expressos em miligramas de equivalentes de ácido gálico por grama de amostra. A extração e determinação dos carotenoides totais foram realizadas pelo método descrito por Rodriguez-Amaya \& Kimura ${ }^{21}$ em triplicata, sendo a leitura realizada no espectrofotômetro a $450 \mathrm{~nm}$. Os resultados foram expressos em miligrama de carotenoides por 100 gramas de amostra.

Os resultados dos testes de escala hedônica, atividade antioxidante, fenólicos e carotenoides totais foram tratados pela análise de variância (ANOVA) e pelo teste de Tukey. O software Statgraphics foi utilizado nas análises estatísticas, e valores de $p<0,05$ foram considerados significativos.

\section{Resultados e Discussão}

Os resultados obtidos no teste de escala hedônica mostram que o kefir com geleia de goiaba obteve pontuação média entre "2" e "3", que correspondem aos descritores "gostei muito" e "gostei moderadamente" da escala hedônica decrescente de nove pontos utilizada no estudo (figura 1). Os consumidores, portanto, aceitaram a bebida fermentada e apontaram o sabor como o atributo mais gostado (37\%), seguido do aroma (25\%), aceitação global (24\%) e consistência (18,5\%). Como mencionado por Garcia ${ }^{12}$ sobre a adição de frutas, a adição da geleia de goiaba amenizou o sabor ácido característico do kefir, conferindo dulçor e equilíbrio ao produto, proporcionando maior aceitação sensorial pelos consumidores que não apreciam o sabor do leite fermentado em sua 
forma natural. Em relação ao teste de intenção de compra (figura 2), o kefir com geleia de goiaba recebeu a média ponderada de 3,03, correspondente à categoria "compraria frequentemente". Este resultado aponta para as perspectivas de consumo dessa bebida fermentada, se comercializada e apresentada ao consumidor como produto alimentício com potencial propriedade funcional.

A caracterização do kefir com geleia de goiaba (umidade, proteínas, lipídios, cinzas e glicídios totais) e o valor energético em 100 gramas e por porção do produto são apresentados na tabela 1. Do ponto de vista nutritivo, 100 gramas desse produto lácteo contêm, aproximadamente, $75 \mathrm{kcal}$, enquanto uma porção de 170 gramas fornece aproximadamente 127,9kcal. Esses valores são pouco maiores do que o do iogurte natural de fruta, que apresenta 70kcal em 100 gramas e 119kcal na porção de 170 gramas. ${ }^{22}$

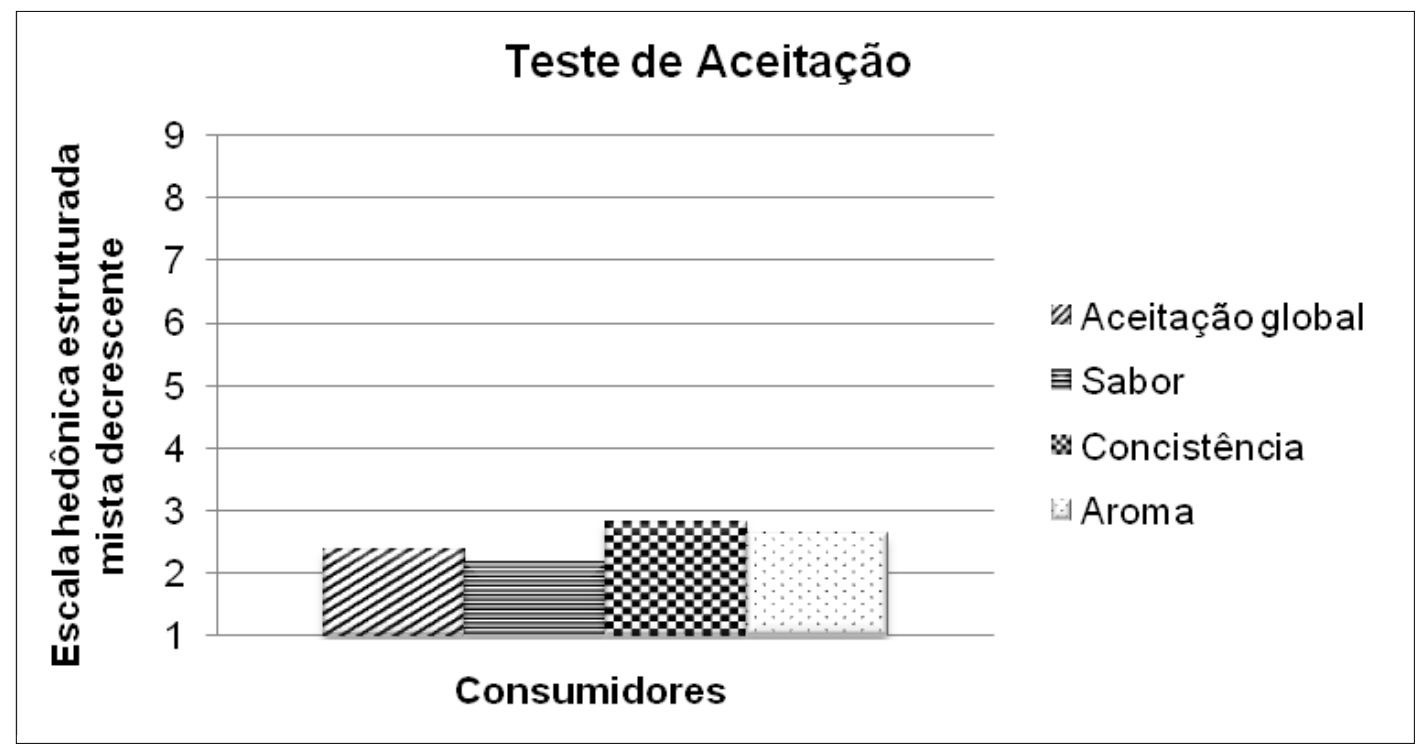

Figura 1. Valores das médias ponderadas dos pontos recebidos por cada um dos atributos avaliados no teste de aceitação do kefir com geleia de goiaba. 


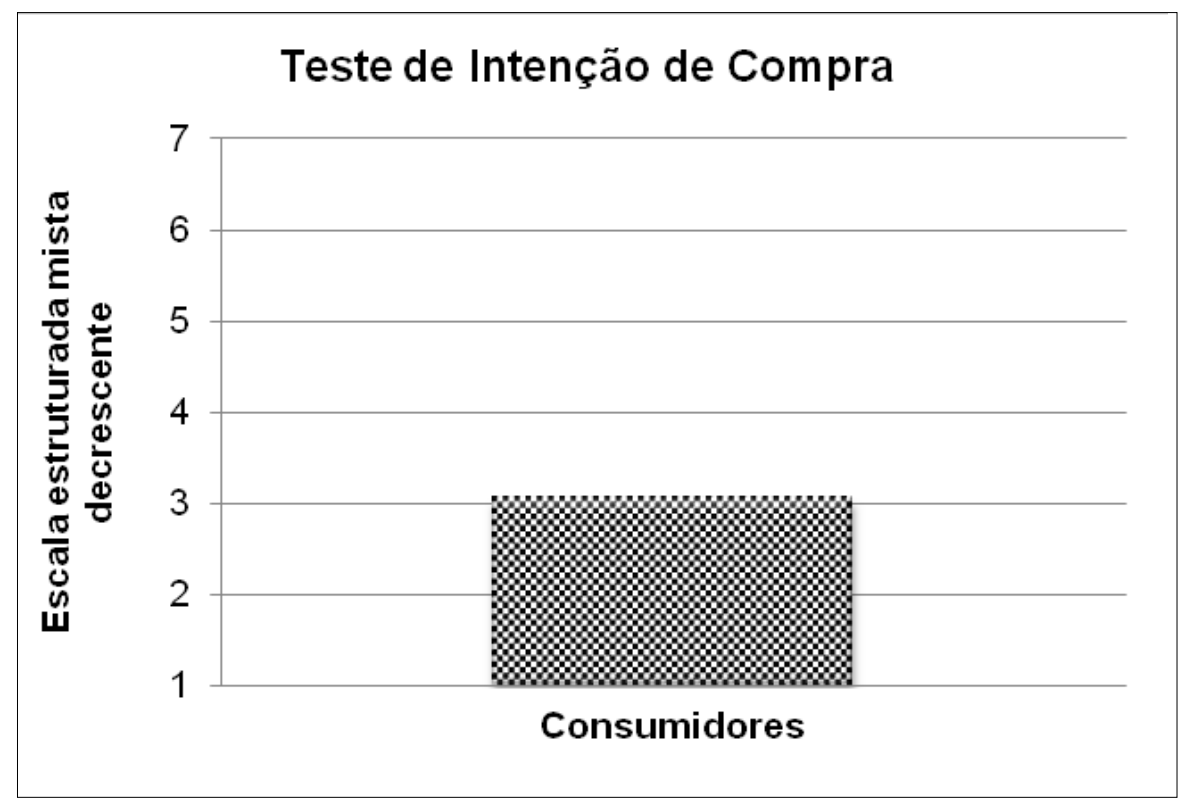

Figura 2. Valores das médias ponderadas dos pontos recebidos no teste de intenção de compra do kefir com geleia de goiaba.

Tabela 1. Composição e valor energético de kefir com geleia de goiaba em 100 gramas e por porção. Niterói-RJ, 2017.

\begin{tabular}{ccc}
\hline Composição & Centesimal $(\mathbf{g} / \mathbf{1 0 0 g})$ & Porção $(\mathbf{g} / \mathbf{1 7 0 g})$ \\
\hline Umidade & $80,87 \pm 0,02$ & 137,48 \\
Proteínas & $3,22 \pm 0,08$ & 5,47 \\
Lipídios & $0,25 \pm 0,01$ & 0,43 \\
Cinzas & $0,63 \pm 0,01$ & 1,07 \\
Glicídios $^{1}$ & 15,03 & 25,55 \\
VET $^{2}$ & 75,25 & 127,95 \\
\hline
\end{tabular}

$\overline{\text { Valores médios } \pm \text { desvio-padrão (DP); } \mathrm{n}=3 \text { (triplicata de análise); }{ }^{1} \text { por diferença, }{ }^{2}=\text { valor energético total em } \mathrm{kcal} / 100 \mathrm{~g}}$ 
A avaliação da atividade antioxidante das amostras de kefir, geleia de goiaba e kefir com geleia de goiaba apresentaram, respectivamente, os valores 38,9; 138,4 e 165,5 $\mu \mathrm{mol}$ de equivalentes de trolox por grama da amostra (figura 3). Observou-se, portanto, que a adição dos $30 \%$ de geleia de goiaba ao kefir aumentou a atividade antioxidante em 74,5\% e 16,5\%, quando comparado ao kefir puro e à geleia pura, respectivamente. O estudo realizado por Melo et al. ${ }^{23}$ mostra que o extrato acetônico da goiaba exibiu alta atividade antioxidante, devido à forte capacidade de sequestrar o radical indutor de oxidação DPPH, sendo superior a $70 \%$.

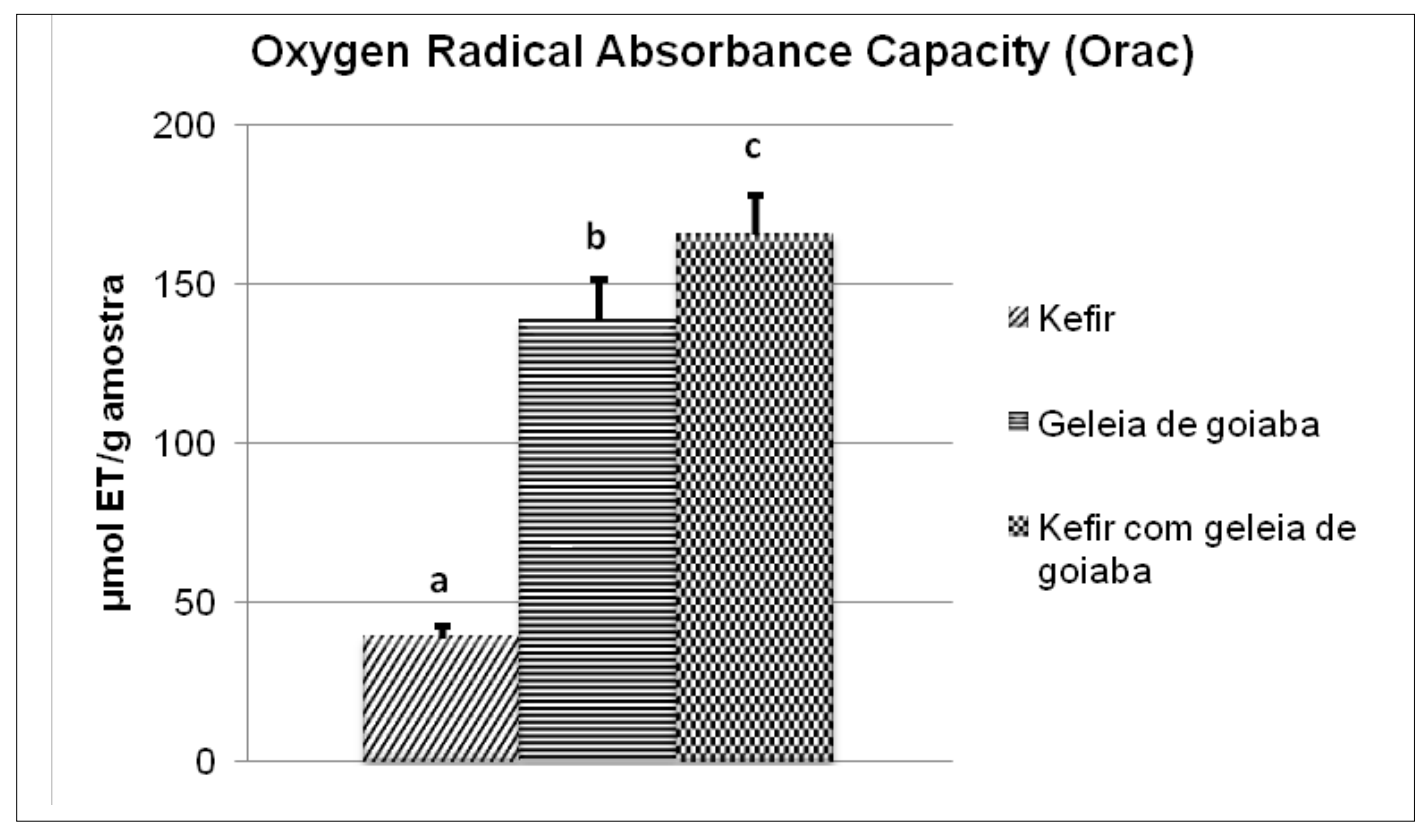

Figura 3. Valores da atividade antioxidante dos extratos do kefir, da geleia de goiaba e do kefir com geleia de goiaba pelo ensaio ORAC. Letras minúsculas diferentes indicam diferença significativa $(\mathrm{p}<0,05)$.

Valores da concentração de fenólicos totais dos extratos do kefir, da geleia de goiaba e do kefir com geleia de goiaba podem ser observados na figura 4. É sabido que as frutas, sobretudo aquelas de cor avermelhada e azulada, ${ }^{24}$ apresentam alto teor e diferentes classes de compostos fenólicos, principalmente devido à presença de pigmentos antocianínicos, que são responsáveis pela coloração vermelha, púrpura e violeta. Essas são, portanto, importantes fontes de compostos fenólicos, potencializando os efeitos biológicos benéficos que o consumo de frutas traz ao organismo. A goiaba é uma das frutas com essa propriedade. ${ }^{14}$ 


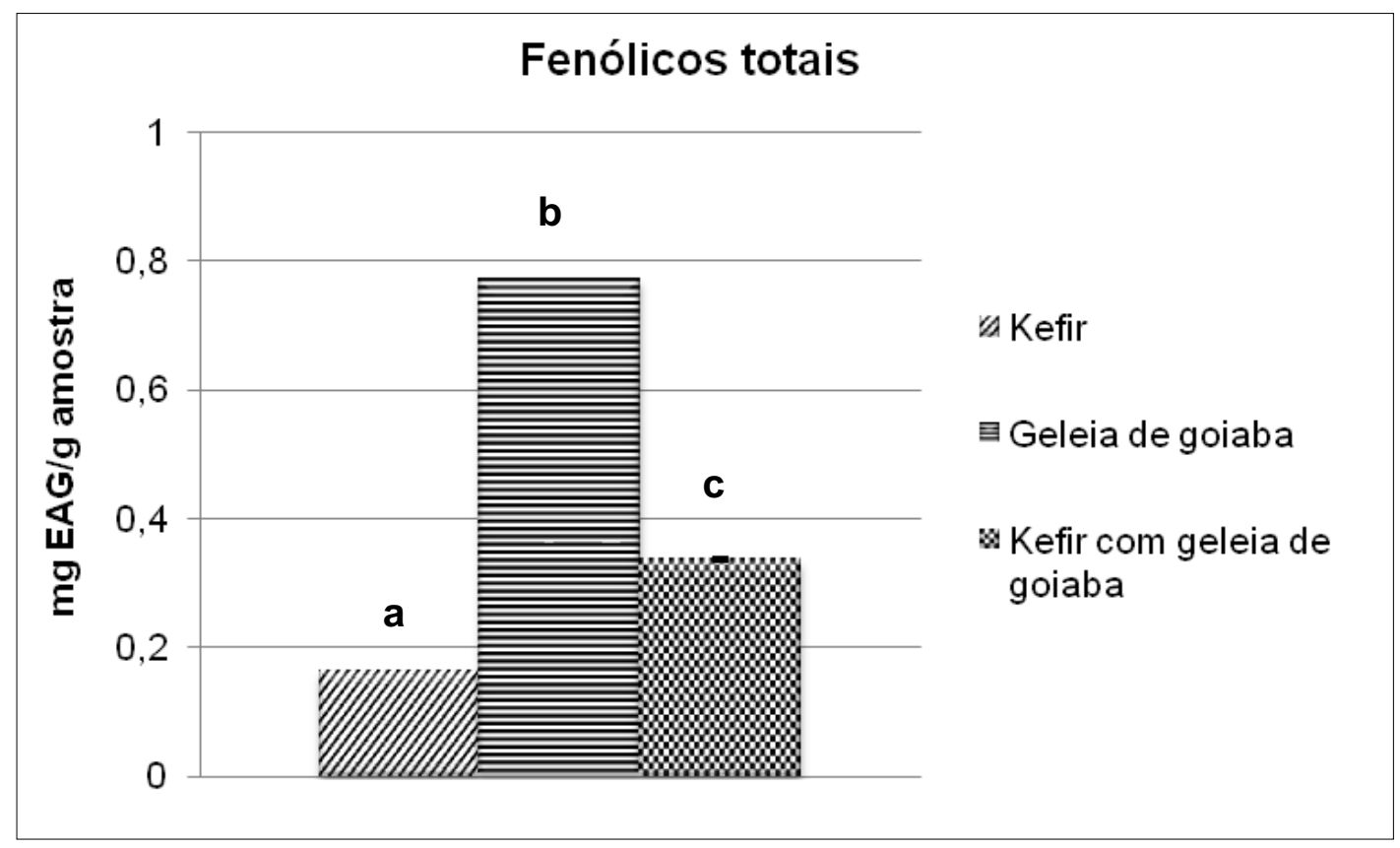

Figura 4. Valores da concentração de fenólicos totais dos extratos do kefir, da geleia de goiaba e do kefir com geleia de goiaba pelo método espectrofotométrico. Letras minúsculas diferentes indicam diferença significativa $(p<0,05)$.

Neste estudo, foi obtido valor mais elevado de fenólicos totais no kefir com geleia de goiaba $\left(0,33 \mathrm{mgEAG} \cdot \mathrm{g}^{-1}\right)$ do que no kefir puro $\left(0,16 \mathrm{mgEAG} \cdot \mathrm{g}^{-1}\right)$. Cheuczuk \& Rocha ${ }^{25}$ encontraram resultado semelhante em um estudo envolvendo soro de leite fermentado e polpa de cajá-manga. Entretanto, a geleia de goiaba pura obteve valor mais elevado que o kefir com geleia de goiaba. A geleia de goiaba, mesmo tendo sofrido cocção e adição de sacarose durante sua elaboração, ainda apresentou valor de fenólicos totais mais elevados $\left(0,77 \mathrm{mgEAG} . \mathrm{g}^{-1}\right)$ que aqueles obtidos para o kefir e para o kefir com geleia de goiaba. Esse resultado pode ser explicado pela interação que os peptídeos e as proteínas lácteas podem realizar com os compostos fenólicos, levando a dificuldades na quantificação desses compostos pelo método de análise utilizado nesse estudo. ${ }^{26}$ Há poucos estudos que expliquem essa possível influência sobre o método de análise, sendo necessários mais estudos científicos.

Os resultados obtidos na análise dos carotenoides totais dos extratos do kefir, da geleia de goiaba e do kefir com geleia de goiaba pelo método espectrofotométrico podem ser verificados na figura 5. Há semelhança entre os compostos fenólicos totais, pois o valor obtido para a geleia de 
goiaba $(12,69 \mathrm{mg} / 100 \mathrm{~g})$ foi superior aos valores obtidos para o kefir $(6,75 \mathrm{mg} / 100 \mathrm{~g})$ e para o kefir com geleia de goiaba $(10,13 \mathrm{mg} / 100 \mathrm{~g})$. O resultado do presente estudo foi semelhante ao de Moura Filho, ${ }^{27} \mathrm{em}$ que a elaboração da bebida láctea com fruta resultou em produto com conteúdo em carotenoides inferior ao da fruta.

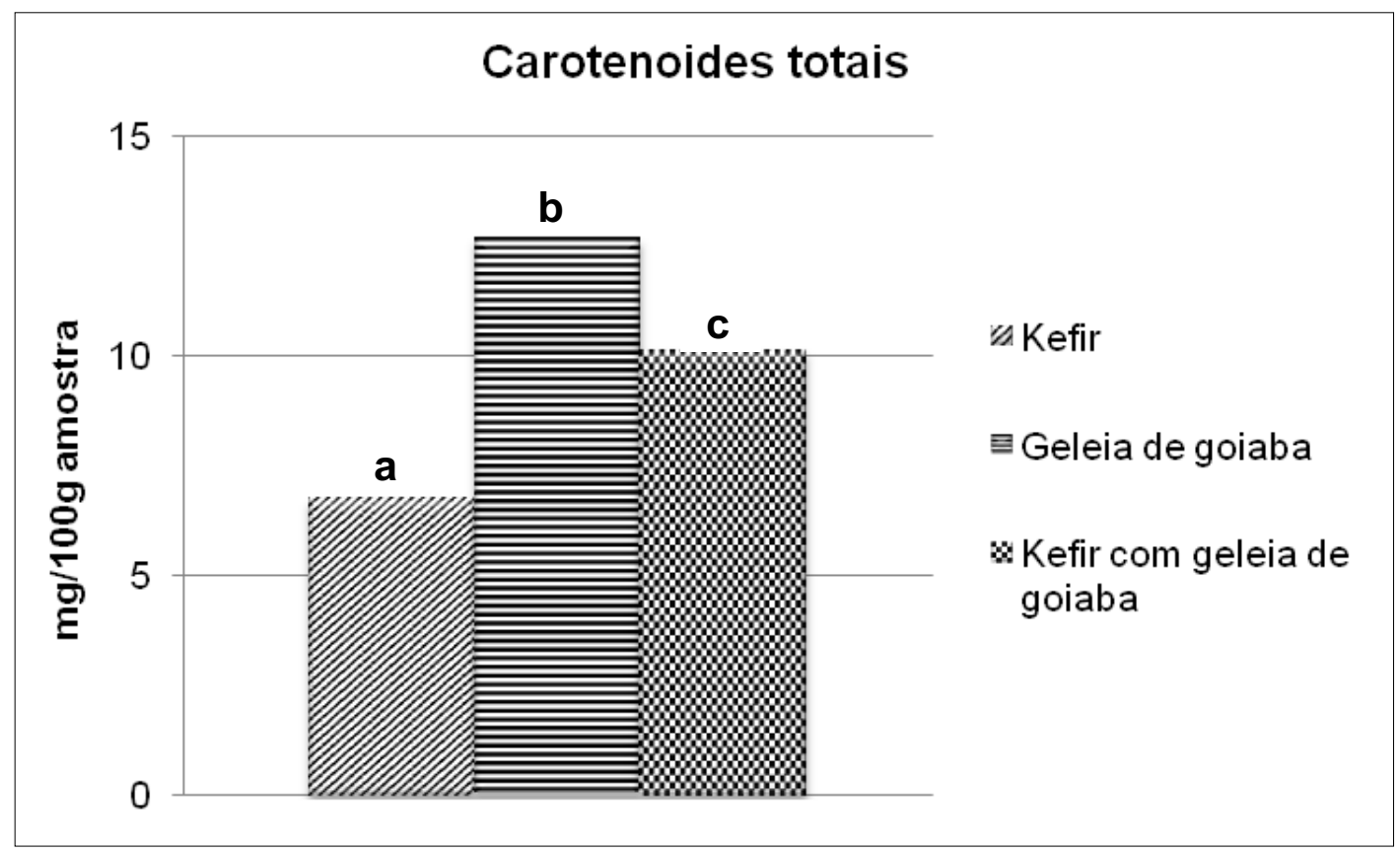

Figura 5. Valores da concentração de carotenoides totais dos extratos do kefir, da geleia de goiaba e do kefir com geleia de goiaba pelo método espectrofotométrico. Letras minúsculas diferentes indicam diferença significativa $(p<0,05)$.

Estes resultados estão possivelmente relacionados com a interação dos peptídeos e das proteínas lácteas com os carotenoides. ${ }^{26}$ Entretanto, uma comparação entre o kefir e o kefir com geleia de goiaba mostra que a fruta, na forma de geleia, agregou compostos bioativos ao kefir puro. É preciso considerar, também, que as proteínas e polissacarídeos produzidos pelas bactérias probióticas do kefir ${ }^{7}$ vêm se somar aos compostos bioativos oriundos da fruta, resultando em um produto alimentício que pode contribuir para a saúde dos consumidores. 


\section{Conclusão}

O kefir com geleia de goiaba foi aceito pelos consumidores, que comprariam o novo produto caso ele fosse comercializado. O kefir acrescido com $30 \%$ de geleia de goiaba apresentou atividade antioxidante maior que o kefir e a geleia de goiaba isoladamente, sendo, portanto, uma boa fonte de compostos antioxidantes. A adição de geleia de goiaba propiciou também o aumento do conteúdo em compostos fenólicos e carotenoides no kefir.

Desta forma, podemos concluir que essa bebida fermentada poderia contribuir para a saúde dos consumidores. Recomendamos a realização de estudos concernentes às condições ótimas de embalagem e armazenamento desse produto lácteo, visando à segurança higiênico-sanitária e à preservação do seu valor nutritivo.

\section{Colaboradores}

CS Cavararo participou do desenho do estudo, execução e interpretação dos resultados das análises, da redação do artigo até sua versão final; CCJ Chiappini trabalhou da concepção e desenho do estudo, orientação e interpretação dos resultados da análise sensorial e redação e revisão do artigo até sua versão final; JR Domingues participou do desenho do estudo, orientação e interpretação dos resultados das análises de atividade antioxidante, fenólicos totais e carotenoides totais, revisão do artigo até sua versão final; JS Pinho Jr contribuiu para a realização das análises de atividade antioxidante, fenólicos totais e carotenoides totais e da interpretação dos resultados.

Conflitos de interesses: Os autores declaram que não haver conflito de interesses.

\section{Referências}

1. Brunari NC, Salotti-Souza BM. Bactérias probióticas e sua aplicação em leites fermentados. Rev Cient Med Vet. 2017; 1(1):22-29.

2. Brasil. Agência Nacional de Vigilância Sanitária. Regulamento Técnico de Substâncias Bioativas e Probióticos Isolados com Alegação de Propriedades Funcional e ou de Saúde. Resolução no 2, de 07 de janeiro de 2002. Diário Oficial da União, 9 jan. 2002.

3. Food and Agriculture Organization. Report of a Joint FAO/WHO expert consultation on evaluation of health and nutritional properties of probiotics in food including powder milk with live lactic acid bacteria. Córdoba: FAO; WHO; 2001. 34 p.

4. Schrezenmeir J, De Verse M. Probiotics, prebiotics, and synbiotics: approaching a definition. Am J Clin Nutr. 2001; 73(2):361-364.

5. Cruz AG, Buriti FCA, Souza CHB, Faria JAF, Saad SMI. Probiotic cheese: health benefits, technological and stability aspects. Trends Food Sci Technol. 2009; 20(8):344-354. 
6. Brasil. Ministério da Agricultura, Pecuária e do Abastecimento. Instrução Normativa no 46, de 23 de outubro de 2007. Regulamento Técnico de Identidade e Qualidade de Leites Fermentados. Diário Oficial da União, 23 out. 2007.

7. Nielsen B, Gürakan GC, Ünlü G. Kefir: a multifaceted fermented dairy product. Probiotcs and Antimicro. Prot. 2014; 6(3-4):123-135.

8. Lima MSF, Silva RA, Silva MF, Porto ALF, Cavalcanti MTH. Características microbiológicas e antioxidantes de um novo alimento funcional probiótico: leite de ovelha fermentado por kefir. XX Congresso de Engenharia Química; 2014; Florianópolis. Resumo.

9. Bourrie BCT, Willing BP, Cotter PD. The microbiota and health promoting characteristics of the fermented beverage kefir. Front Microbiol. 2016; 7:1-17.

10. Prado MR, Blandón LM, Vandenberghe LPS, Rodrigues C, Castro GR, Thomaz-Soccol V, et al. Milk kefir: composition, microbial cultures, biological activities, and related products. Front Microbiol. 2015; 6:1-10.

11. Fung WY, Woo YP, Wan-abdullah WN, Ahmad R, Easa AM, Liong MT. Benefits of probiotics: beyond gastrointestinal health. Milchwissenschaft. 2009; 130(21):48-51.

12. Garcia RV, Travassos ERA. Leite fermentado caprino sabor umbu: elaboração e aceitabilidade. Rev. Inst. Adolfo Lutz. 2012; 71(1):134-139.

13. Lozoya X, Reyes-Morales H, Chávez-Soto MA, Martínez-García MC, Soto-González Y, Doubova SV. Intestinal anti-spasmodic effect of a phytodrug of Psidium guajava folia in the treatment of acute diarrheic disease. J Ethnopharmacol. 2002; 18(3):387-393.

14. Haida KS, Haas J, Mello AS, Haida KS, Abrão RM, Sahd R. Compostos Fenólicos e Atividade Antioxidante de Goiaba (Psidium guajava L.) Fresca e Congelada. Rev. Fitos. 2015; 9(1):1-72.

15. Cruz AG, Cadena RS, Castro WF, Esmerino EA, Rodrigues JB, Faria JAF, et al. Consumer perception of probiotic yogurt: performance of check all that apply (CATA), projective mapping, sorting and intensity scale. Food Res. Int. 2013; 54(1):601-610.

16. Meilgaard M, Civille GV, Karr BT. Sensory evaluation techniques. 4th ed. Boca Raton: CRC Press; 2006. 464 p.

17. Horwitz W. editor. Official methods of analysis of Association of Official Analytical Chemistis. $17^{\text {th }}$ ed. Gaithersburg: AOAC International; 2000.

18. Ribeiro OAS, Boari CA, Fonseca CM, Figueiredo SP, Abreu LRA, Neumann D. Bebida láctea fermentada formulada com Camellia sinensis. Boletim CEPPA. 2014; 32(2):289-304.

19. Dávalos A, Gómez-Cordovés C, Bartolomé B. Extending applicability of the oxygen radical absorbance capacity (ORACfluorescein) assay. J Agric Food Chem. 2004; 52(1):48-54.

20. Singleton VL, Joseph AR. Colorimetry of total phenolics with phosphomolybdic-phosphotungstic acid reagents. Am J Enol Vitic. 1965; 16:144-158.

21. Rodriguez-Amaya DB, Kimura M. Harvestplus handbook for carotenoid analysis. Washington, DC: HarvestPlus; 2004. Technical Monograph Series 2.

22. Universidade Estadual de Campinas. Núcleo de Estudos e Pesquisas em Alimentação. Tabela brasileira 
de composição de alimentos. $4^{\mathrm{a}}$ ed. Campinas: UNICAMP/NEPA; 2011.

23. Melo EA, Maciel MIS, Lima VLAG, Nascimento RJ. Capacidade antioxidante de frutas. Rev Bras Ciênc Farm. 2008; 44(2):193-201.

24. Degáspari CH, Waszczynskyj N. Propriedades antioxidantes de compostos fenólicos. Visão Acad. 2004; 5(1):33-40.

25. Cheuczuk F, Rocha LA. Propriedades antioxidantes de bebida láctea fermentada prebiótica incorporada de polpa de cajá-manga. [Trabalho de Conclusão de Curso] Paraná: Universidade Tecnológica Federal Do Paraná, Curso de Tecnologia em Alimentos; 2014.

26. Libardi SH, Cardoso DR. Aspectos da interação entre compostos fenólicos e proteínas do soro do leite e a sua influência na atividade antioxidante do produto. [Dissertação] São Paulo: Instituto de Química de São Carlos, Programa de Pós-Graduação em Química Analítica; 2009.

27. Moura Filho JM. Preparado de buriti (Mauritia flexuosa L): produção, caracterização e aplicação em leite fermentado. [Dissertação] São Paulo: Universidade Estadual Paulista "Júlio de Mesquita Filho", Pós-Graduação em Engenharia e Ciência de Alimentos; 2017.

Recebido: 15 de novembro, 2017

Revisado: 23 de abril, 2018

Aceito: 24 de maio, 2018 
